\title{
VIVÊNCIAS FORMATIVAS E PRÁTICAS DOCENTES: UM OLHAR SOBRE O PACTO NACIONAL PELA ALFABETIZAÇÃO NA IDADE CERTA
}

http://dx.doi.org/10.5902/2318133823486

\author{
Evanir Agostinho de Oliveira \\ Ana Carla Hollweg Powaczuk \\ Universidade Federal de Santa Maria, Brasil.
}

\begin{abstract}
Resumo
Neste artigo apresenta-se a pesquisa realizada para conclusão do curso de especialização em Gestão Educacional. O estudo objetivou compreender as vivências que os professores tiveram no processo de formação continuada ofertado pelo programa Pacto Nacional pela Alfabetização na Idade Certa - Pnaic - e a repercussão nas práticas pedagógicas de professoras atuantes no bloco de alfabetização do ensino fundamental - 1ㅜ, $2^{\circ}$ e $3^{\circ}$ ano - da rede municipal e estadual de Santa Maria, RS. O trabalho foi desenvolvido a partir de uma abordagem qualitativa narrativa de cunho sociocultural, utilizando-se para a coleta dos dados entrevistas semiestruturadas, as quais foram realizadas com seis professoras. Os referenciais que embasaram a investigação foram Dourado (2007; 2014), Saviani (2011), Fonseca (2002), Gibbs (2009), Oliveira (2011), Bolzan e Powaczuk (2013), Vaillant e Marcelo (2012), Charlot (2002) e Freire (2002). O estudo permitiu perceber que a repercussão do Pnaic aconteceu sob a perspectiva de reflexões individuais e coletivas acerca das inquietações do trabalho docente. O compartilhamento evidenciou-se como principal aspecto dessa formação. Contudo, os professores manifestaram descontentamento com as ações no que diz respeito às dinâmicas formativas organizadas pelas orientadoras de estudo, bem como às exigências e impactos ao trabalho docente. Assim, conclui-se que a política educacional instituída precisa ser aprimorada em termos de organização das dinâmicas formativas de modo a incrementar os espaços de compartilhamento e de fortalecimento do trabalho docente.

Palavras-chave: políticas educacionais, Pnaic, formação continuada, experiências formativas.
\end{abstract}

\section{EXPERIENCES FORMATION AND PRACTICES LECTURERS: A LOOK OVER THE PACT BY THE NATIONAL LITERACY AT AGE ABSTRACT}

\section{Abstract}

This paper presents the survey for completion of the course of specialization in Educational Management. The study aimed to understand the experiences that teachers had in the process of continuing education offered by the program, the Literacy National Pact in the Middle One - Pnaic and the effect on teaching practices of active teachers in elementary school literacy block - 1, 2 and 3rd year -, the Municipal network and State of Santa Maria, RS. The work was developed from a qualitative narrative approach Cleat Sociocultural, using for data collection semi-structured interviews, which were conducted with six teachers. The references that supported the research were: Gold (2007-2014), Saviani (2011), Fonseca (2002), Gibbs (2009), Oliveira (2011), Bolzan and Powaczuk (2013), Vaillant and Marcelo (2012), Charlot (2002) Freire (2002). The study allowed us to realize that the impact of Pnaic, was given from the perspective of individual and collective reflections on the concerns of the teaching profession. The sharing was evident as the main aspect of this training. However, the teachers expressed dissatisfaction with the actions with 
regard to the formative dynamics organized by guiding study, as well as the requirements and impacts the teaching. Thus, it is concluded that the established educational policy needs to be improved in terms of organization of formative dynamics in order to improve the sharing of space and strengthening of teaching.

Key-words: educational policy, Pnaic, continuous formation, formative experiences. 


\section{Introdução}

O longo das últimas décadas as políticas públicas para a educação básica e superior no Brasil passaram por reestruturações das mais simples as mais complexas, conduzidas por mudanças de várias ordens: aumento populacional, desenvolvimento econômico do país e sociais. Para tal as políticas públicas educacionais vêm sendo repensadas e reformuladas em busca da qualificação do sistema educacional, assim como das ações docentes. Segundo Gatti e Barreto (2009, p.14), "além da importância econômica, o trabalho dos professores também tem papel central do ponto de vista político e cultural. $O$ ensino escolar há mais de dois séculos constitui a forma dominante de socialização e de formação nas sociedades modernas e continua se expandindo". Assim, a formação de professores tem sido constantemente foco nos debates, nos estudos das políticas públicas para a educação básica e superior.

De acordo com Saviani (2011), ao longo dos últimos dois séculos, foram introduzidas sucessivas mudanças no processo de formação docente no Brasil revelando um quadro de descontinuidade, conduzindo a fragmentações no sistema educacional que culminaram em lacunas que expuseram as fragilidades da formação docente.

Nesta direção, torna-se importante buscar possibilidades que possam contribuir para que as políticas públicas e os programas para formação de professores inicial e continuada sejam e implantadas de forma articulada e em cooperação, traduzindo esforços coletivos para que a educação vá ao encontro aos padrões de qualidade tão necessários para o desenvolvimento da sociedade.

Nesta direção, coaduna-se esse estudo que buscou compreender as vivências que os professores tiveram no processo de formação continuada ofertado pelo programa do Programa Nacional Pacto Nacional pela Alfabetização na Idade Certa - Pnaic - e sua influência nas práticas pedagógicas de professoras atuantes no bloco de alfabetização do ensino fundamental da rede municipal e estadual de Santa Maria.

O estudo foi desenvolvido a partir de uma abordagem qualitativa narrativa de cunho sociocultural, utilizando-se de entrevistas semiestruturada. Para Freitas (2002) a narrativa de cunho sociocultural utiliza como ponto de partida a perspectiva sócio-histórica dos acontecimentos e vivências pelas quais o sujeito passa, reconhecendo a singularidade desse processo.

Para atender os objetivos do estudo buscaram-se, como elementos de análise, as entrevistas semiestruturadas, assim como pesquisa bibliográfica. Segundo Fonseca (2002) a entrevista semiestruturada tem como base temas pré-estabelecidos pelo entrevistador para iniciar a exploração da conversa para no decorrer da conversação os desdobramentos farão emergir novos temas. Nesta direção, as entrevistas semiestruturadas foram organizadas a partir de tópicos guias que contemplaram os desafios do trabalho docente, concepção de formação continuada, experiências formativas de destaque, a formação no Pnaic.

Participaram como sujeitos da pesquisa professores atuantes no $1^{\circ}, 2^{\circ}$ e $3^{\circ}$ anos do ensino fundamental, de instituições públicas, da rede estadual e municipal de ensino da cidade de Santa Maria - RS. 


\section{Políticas públicas e a formação continuada de professores}

Segundo Oliveira (2004) as reformas educacionais iniciadas na última década no Brasil trouxeram mudanças significativas para formação continuada dos docentes. Essas atuam não só no nível da escola, mas em todo o sistema, objetivando repercutir em possíveis mudanças no trabalho desenvolvido no contexto escolar. Contudo, sua relação com a qualificação efetiva dos processos educativos carece de comprovações. Segundo Gatti e Barreto (2009)

Há uma grande mobilização em torno do assunto, a produção teórica é crescente, eventos oficiais e não oficiais propiciam debates e razoável circulação de análises e propostas e os sistemas de educação investem cada vez com maior frequência no ensaio de alternativas de formação continuada de professores. Apesar disto, os resultados obtidos com os alunos, do ponto de vista de seu desempenho em conhecimentos escolares, não têm ainda se mostrando satisfatórios, fato que tem posto, no Brasil, os processos de educação continuada em questão. (p. 194)

As modificações mais recentes na organização escolar mostram uma maior flexibilidade, tanto nas estruturas curriculares, quanto nos processos de avaliação, confirmando a ideia de que estamos diante de novos padrões de organização também da prática pedagógica, exigindo um novo perfil do docente. Mas necessita-se observar a distância entre o que é divulgado nos programas de reforma educacional e o que é de fato implantado nas escolas, que nem sempre estão em harmonia. Daí a importância de se chegar até o chão da escola para compreender as mudanças que de fato ocorrem no cotidiano docente (Oliveira, 2004).

O governo tem proposto políticas públicas educacionais em busca de melhorar a educação no Brasil, utilizando o Índice de Desenvolvimento da Educação Básica - Ideb como base de mapeamento do desenvolvimento da educação nacional.

Por esse mapeamento de dados realizado pelo Inep busca-se a melhoria desses resultados, tendo como parâmetro a média seis a ser alcançada até 2022, de acordo com o resultado obtido pelos países da Organização para a Cooperação e o Desenvolvimento Econômico. A partir da análise dos referentes do Ideb há a oferta de apoio técnico e financeiro aos municípios onde os índices ficaram abaixo do esperado de qualidade no ensino.

Nesta direção, é necessário refletir acerca do conceito de política pública de modo a ampliar a compreensão acerca da aplicabilidade das ações desenvolvida. Teixeira (2002, p. 2) afirma que "políticas públicas são diretrizes, princípios norteadores de ação do poder público; regras e procedimentos para as relações entre poder público e sociedade, mediações entre atores da sociedade e do Estado". O autor diz, ainda, que as políticas públicas demonstram em seu processo de elaboração e implantação, sobretudo, em seus resultados, formas de poder político, envolvendo a distribuição e redistribuição de poder, o papel do conflito social nos processos de decisão, a repartição de custos e benefícios sociais.

Para Dourado (2007, p. 925) "políticas educacionais efetivamente implicam o envolvimento e o comprometimento de diferentes atores, incluindo gestores e professores vinculados aos diferentes sistemas de ensino". Considerando-se a afirmação de Dourado, 
fica perceptível a importância de ações colaborativas de maneira que sejam ouvidos todos os envolvidos, nas diversas instâncias educacionais.

Uma das políticas públicas na esfera educacional para formação de professores, em andamento é o Pacto Nacional pela Alfabetização na Idade Certa - Pnaic - que se caracteriza como um acordo assumido pelo governo federal, estados, municípios com vistas a alfabetizar as crianças de até oito anos de idade do ensino fundamental, ao final do ciclo de alfabetização (MEC, 2012).

O Estado do Rio Grande do Sul teve a formação dos orientadores do estudo organizada pela Universidade Federal de Santa Maria, que assumiu o trabalho junto a 314 municípios. O programa direciona-se ao o aperfeiçoamento da formação dos professores alfabetizadores e foi constituído por um conjunto interligado de ações, materiais, referências curriculares e pedagógicas que foram disponibilizadas pelo MEC, sendo seu eixo fundamental a formação continuada de professores alfabetizadores.

De acordo com o documento orientador do Pnaic às questões inicialmente colocadas em discussão foram: estratégias para a melhoria da educação respectiva à delimitação de conhecimentos, habilidades e capacidades a serem contempladas nas propostas curriculares.

Advoga-se para a busca por métodos que permitam qualificar as práticas na alfabetização. Nesta direção, apresenta-se um embasamento conceitual no trabalho de Emília Ferreiro e Ana Teberosky sobre a psicogênese da língua escrita (1984), e sua importância para a compreensão do desenvolvimento do processo da leitura e escrita.

Em busca de atender o desenvolvimento do Pnaic foi recomendado que fossem organizadas equipes de trabalho voltadas especificamente para planejar, monitorar e realizar ações no âmbito do ciclo de alfabetização em duas instâncias, para tal indicou-se essa formação à equipe central, das Secretarias Municipais e Estadual de Educação Equipes nas escolas.

Essas teriam como função principal a definição de princípios gerais e construção de orientações globais de trabalho, assim como a articulação entre as unidades escolares. Também deveriam definir planos de ação para cada unidade escolar, assim como coordenar o trabalho coletivo, no universo das unidades. Para fundamentar essa articulação entre as instâncias foi sugerida a criação de um conselho ou um núcleo de alfabetização, que se responsabilizaria pela discussão das políticas da rede de ensino destinadas ao atendimento das crianças dos anos iniciais.

Para que de fato as aprendizagens fossem garantidas foi necessário investir no planejamento, possibilitando maior articulação dos conhecimentos desenvolvidos nas diferentes etapas de escolaridade. Os alfabetizadores precisariam atender aos seguintes critérios para atuação nos anos iniciais do ensino fundamental:

Ter domínio dos conhecimentos necessários ao desenvolvimento do ensino da leitura e a escrita na perspectiva do letramento; Habilidades para interagir com as crianças, dinamizando o processo pedagógico e promovendo situações lúdicas de aprendizagem; Assiduidade e pontualidade, evidenciando compromisso com os processos pedagógicos; Sensibilidade para lidar com a diversidade social, cultural, de gênero e etnia. (MEC, 2012, p. 12) 
Enfatizou-se a importância do estabelecimento de uma política de formação continuada para docentes, gestores e profissionais que apoie à docência. A formação continuada diversificada, com ações de diferentes tipos que atendesse às demandas dos profissionais quanto aos saberes da docência. Para tanto, destaca-se como necessário a definição de políticas de formação que tome como base os resultados das avaliações realizadas e garantindo que na formação continuada o cotidiano da sala de aula, ou seja, a prática docente seja objeto central de atenção. A teorização da prática necessita compor o eixo central das ações formativas. Os projetos de formação continuada deveriam ter seu fortalecimento na escola, a constituição de espaços e ambientes educativos que possibilitassem a aprendizagem reafirmando a escola como espaço do conhecimento, do convívio e da sensibilidade, condições imprescindíveis para a construção da cidadania (MEC, 2012).

\section{Formação continuada e a repercussão na prática docente}

A formação continuada vem sendo discutida a um longo tempo e diversos estudos vem dedicando a refletir a temática, ainda demostrando-se um campo com muitos pontos a ser pensar e repensados, pois vivemos em progressiva mudança o que conduz a necessidade de estar revisitando saberes, em busca de qualificar os sujeitos e o mundo.

De acordo com Saviani (2011) o contexto de formação continuada no Brasil, ao longo das últimas décadas, constitui-se a partir sucessivas mudanças no processo de formação docente. A questão pedagógica, inicialmente ausente, vai adentrando ao poucos, até ocupar posição central. Nóvoa (2009) afirma que

é importante assegurar que a riqueza e a complexidade do ensino se tornem visíveis, do ponto de vista profissional e científico, adquirindo um estatuto idêntico a outros campos de trabalho académico e criativo. $E$, ao mesmo tempo, é essencial reforçar dispositivos e práticas de formação de professores baseadas numa investigação que tenha como problemática a ação docente e o trabalho escolar. (p. 19)

Contudo, de acordo com Saviani (2011), o contexto da formação continuada no Brasil não encontrou, até hoje, um encaminhamento satisfatório, revelando desta forma permanente a precariedade das políticas formativas. As sucessivas mudanças não conseguiram estabelecer um padrão minimamente sólido para preparação docente, para o trabalho frente aos problemas enfrentados pela educação escolar em nosso país.

Nesta direção, ressalta-se para a necessidade de construção de propostas que contemplem as diferentes realidades que são produzidas do contexto escolar. De acordo com Nóvoa (2009) as propostas teóricas somente poderão produzir sentido se forem construídas dentro da profissão, assim como forem apropriadas a partir de uma reflexão dos professores sobre o seu próprio trabalho. Percebe-se que a formação pensada sem considerar a realidade direta do trabalho docente provavelmente trará pouco resultado.

Os estudos de Charlot (2007) colaboram para a compreensão da formação continuada ao enfatizar a condição do homem como um ser incompleto. Aprender faz parte do processo de pertencimento de um conjunto de relações e processos que compõem um sistema de sentido, que diz quem é o sujeito para o mundo e quem são os outros. 
Assim, pode-se pensar a formação como uma construção de si, uma autoprodução, somente possibilitada pela mediação do outro e com sua ajuda. A formação se desenvolve e se processa no sujeito com a permissão, colaboração, com o investimento pessoal do sujeito.

Nesse sentido, considera-se que o professor, ao assumir-se como aprendiz do seu trabalho, reconhece que o ensinar exige uma postura fundamentada na investigação, assim como no trabalho colaborativo, pois o aprender de sua profissão se dá na interação com outros com os quais interatua. Para tal o professor precisa ter clareza de seus saberes, assim como de suas lacunas para que a formação continuada venha como qualificador das ações pedagógicas. O conhecer-se é ponto de partida para construir-se para docência e na docência.

De acordo com Freire (2002) o discurso sobre a teoria deve ser o modelo concreto, sua personificação, sendo a formação continuada à maneira de manter-se em constante reflexão sobre a prática docente, de modo que essa possa ser oxigenada. A disposição de aprender está intrinsecamente conectada a de ensinar, toda a prática educativa emerge de um sujeito que ensinando aprende, aprendendo ensina. Desse modo, é também aprendente, pois essa relação não se regula em um único sujeito, mas sim em compartilhamento de saberes, que se desdobra reciprocamente ao longo do processo educativo.

Para Vaillant e Marcelo, (2012) o conceito formação precisa conectar-se a capacidade, assim como com a vontade, do indivíduo, a pessoa, sendo esse responsável pela ativação e desenvolvimento dos processos formativos. Isso não quer dizer que a formação seja necessariamente autonomia, pois é através da formação mutua que os sujeitos podem encontrar e organizar contextos de aprendizagem, que favorecem a busca de possibilidades de aperfeiçoamento pessoal e profissional.

Para que seja produzida uma ação de formação é preciso que se construam mudanças por uma interferência pela qual há participação consciente do educando, assim como uma vontade de ambos os atores do processo para conseguirem os objetivos apontados. (Vaillant; Marcelo, 2012).

\section{A formação continuada na perspectiva de professores da rede municipal e estadual de educação do município de Santa Maria}

Ao objetivar identificar as influências do Pnaic nas práticas pedagógicas de professoras atuantes no bloco de alfabetização do Ensino Fundamental da rede municipal de Santa Maria, considera-se imprescindível reconhecer como as professoras compreendem a formação continuada.

Considera-se a formação continuada a partir da perspectiva de Nóvoa (2002), Vaillant e Marcelo (2012), Marcelo (2010) os quais indicam a intrínseca relação entre a dimensão pessoal e a social da profissão. Abrange dimensões auto, inter e hetero formativos, nos quais as ações e a indução aos investimentos formativos se dão a partir do modo como os professores significam as demandas da profissão docente ao longo de sua atuação.

Os participantes deste estudo argumentam sobre a formação continuada como uma necessidade constante, de estar sempre em busca de saberes que conduza a sanar possíveis dúvidas, sendo que nada está dado, completo, fechado. Encontram-se, nesta 
direção, nas narrativas docentes a premissa de que a formação produza direcionamentos específicos que venham a favorecer a atuação enquanto docente, demonstrando o anseio dos docentes que a formação continuada vá ao encontro com sua prática pedagógica.

De acordo com Vaillant e Marcelo (2012) existe um fator que determina que o sujeito aprenda ou não: esse fator é denominado como vontade de melhorar ou de mudar. Logo, a motivação para mudança é o elemento que define que qualquer indivíduo arrisque-se a olhar para o outro lado do espelho.

As professoras colaboradoras do estudo manifestam em suas narrativas uma concepção de formação pautada na ideia da continuidade e do acabamento:

É o processo que o sujeito precisa se constituir como alguém que é incompleto, que busca que corre atrás, que quer tirar dúvidas, que quer aprender sobre o assunto ou renovar as ideias sobre seu fazer, sobre suas atividades, então eu acho que a formação continuada precisa se constituir dessa forma, precisa ter essa caraterística que é própria de cada sujeito, que a própria pessoa tem que buscar. (sujeito B rede Municipal)

A formação continuada é fundamental, para que tu vás atualizando para poder ir revendo todos os teus conceitos, as tuas práticas, mas acho que também não é a formação continuada pela formação continuada, por vezes aqui no governo do estado, tenho experiência lá do Município de Porto Alegre temos palestra, temos isso, temos aquilo, mas atividades soltas que não são direcionadas para os teus interesses, para as tuas necessidades, a formação continuada pela formação continuada só para tu teres uma titulação a mais para comprovar, quando eu penso a formação continuada penso em algo focado, direcionado para as necessidades que a gente tem, essa demanda de hoje. (professora $\mathrm{C}$, rede Estadual).

Nóvoa (2009), ao problematizar os modelos impositivos de formação, afirma que os dispositivos burocráticos no exercício da profissão não são mera questão técnica ou administrativa. Nesta perspectiva pode-se dizer que a exigência de formação perpassa em alguma medida pela possibilidade de controle sobre o como e quando os docentes produzem sua formação.

Estes aspectos estão presentes nas narrativas docentes, levando-as à defesa de uma formação agenciada pelos próprios professores:

O que acontece, acho que se a formação partisse dos professores, eles construíssem, os mesmos fizessem a própria formação, teria muito mais significado e atrairia mais, não se tem sentido essa formação. Muita formação que a gente vem aqui assisti uma palestra duas horas de noite e a gente sai com mesma visão de antes elas não mobilizam a gente para pensar coisas novas, por que elas não nos interessam. Eu acho que tente se repensar como se fazer essa formação continuada, da onde partir, partem do que acham que é importante, mas que realmente, de fato pode não ser, tem que se transformar isso. (professora B, rede Estadual)

Trocas de experiências, criação de coisas, sugestões, não formação fora da escola, dentro da escola é nossa reunião, a reunião pedagógica uma vez por mês, a trocas com as colegas acontecem na hora do recreio, às vezes sai da sala e vai bater. (professora $\mathrm{C}$ rede Municipal) 
Marcelo (2009) afirma que a identidade profissional como sendo a maneira como os professores se definem a si mesmos e aos outros, uma construção do seu eu profissional, em uma progressão ao longo da sua carreira docente e que define a construção do ser docente.

Nesta direção as professoras colaboradoras deste estudo são unânimes em defender a formação em serviço, ou seja, uma formação que ocorre durante o exercício da profissão e que tem a escola como locus primeiro para a promoção de discussões sobre práticas pedagógicas.

Destacam-se as experiências de formação a partir dos encontros organizados nos grupos de estudo do Pnaic, bem como sobre a repercussão das experiências formativas nas práticas docentes. Motiva-se por estabelecer o processo de formação continuada de modo a estabelecer conexões com a ação profissional, tornando-se parte intrínseca do desenvolvimento do docente, possibilitando a produção de reflexões em suas práticas.

Entretanto, as prerrogativas do programa precisam ser analisadas a partir das múltiplas ações que compõe a concretização do programa e especialmente o modo como os professores que vivenciam a formação a percebem.

A professora $\mathrm{B}$ e $\mathrm{C}$, ao referir-se a sua participação no programa, apresentam um posicionamento satisfatório ao mesmo:

É uma iniciativa muito boa, é uma política pública muito interessante e realmente muito importante para nossa formação. O material do Pacto foi muito legal, os trabalhos que a gente realizava, as propostas de grupo de coletivo eram as mais interessantes, porque envolvia independente da série de atuação todo mundo praticava junto. (Professora B, rede estadual)

O PNAIC, a partir das reuniões, das parcerias, das trocas, das parcerias com as colegas conseguimos ter um norte na parte da linguagem, atividades, na parte da matemática que foi excelente, isso abriu o leque, a partir dai eu consegui deslanchar. (Professora $\mathrm{C}$ rede estadual)

As professoras reafirmam o compartilhamento de saberes como ponto mais significativo no processo formativo ofertado pelo Pnaic. As narrativas expressam o compartilhamento como elemento fundamental da formação docente e, ao favorecer esses encontros dos grupos de estudo, o Pnaic propiciou o compartilhamento de saberes tornando as reflexões pessoais e coletivas significativas ao grupo:

Com o PNAIC, tive a possibilidade de estar com um grupo de professoras do primeiro ano e poder compartilhar ideias, poder ver como elas trabalham, quais são as angústias que elas têm, a gente chega a conclusão que são as mesmas que nós temos. Então isso para mim era o mais significativo, de poder estar lá no sábado de manhã e de tarde poder ter aula com um grupo de professores, essa possibilidade de poder compartilhar com esse grupo, de poder estar em formação realmente discutindo sobre aquilo que é necessidade daquele grupo, que talvez sejam necessidades muito semelhantes ou talvez sejam especificas de um contexto e as possibilidades do professor dar uma ideia, olha: quem sabe tu fazes isso, eu fiz deu certo, ou quem sabe a gente pensa em outras estratégias, essa possibilidades de compartilhar isso faz parte da formação. (professora $B$, rede municipal) 
Motivou assim, tu estás no caminho certo continua, melhora aqui, por que teve uma colega que deu uma contribuição, por que ela trabalha de uma forma diferente tua, mais enriquecedora, então nesse sentido, contribuiu, motivou para que tu continues na caminhada, que tu melhores um pouco mais, mas o que trouxe de benefício para dentro da escola foi só isso. (professora A, rede municipal)

As narrativas docentes apontam para exigências impostas para efetivação das ações formativas do programa. Exigências que foram consideradas inadequadas, mas que foram compreendidas como sendo a maneira que as instituições gestoras perceberam como possibilidade de promover uma formação continuada em grande escala:

No momento em que eu imponho que obrigo, que exijo, coloco isso como uma forma de pressionar se perde totalmente o sentido do trabalho são coisas que precisam ser avaliadas, que o curso, que o programa, sim é muito valido o encaminhamento que o Município esteja dando é que precisa ser repensado. Eu vi muitas exigências dentro do processo de formação no PNAIC, acho que algumas foram necessárias, talvez não bem encaminhadas, mas necessárias. (Professora B, rede municipal)

PNAIC se a gente for ler os materiais do Pnaic tem essa exigência de que o professor deva permanecer ou não se não permanecer no curso, isso é um entendimento e uma forma que eles acharam de exigir dos professores que permanecem. Então, fico me perguntando até que ponto essa exigência é valida, acho que tem que partir das pessoas esse interesse e essa motivação. (Professora B, rede municipal)

As professoras apontam que a abordagem que foi desenvolvida pelos gestores locais do programa pode ter sido equivocada, especialmente pela imposição gerada a adesão ao programa dos professores atuantes no bloco de alfabetização. Aliado a estes aspetos também evidenciaram manifestações por parte das professoras no que se refere às dinâmicas das reuniões dos grupos de estudo que foram organizadas na formação:

A minha experiência pessoal, não foi boa devido à orientadora, por que ela não tinha experiência, era uma professora de ensino médio ensinando professoras de anos iniciais, ela atuava no colégio M., deu aula muitos anos atrás lá no tempo da pedra, ela tinha em mãos coisas materiais muito ricos, mais não sabia dinamizar, ela não tinha uma metodologia adequada. A formação acabou sendo feito como trabalhinhos, por que ela não vinha, trabalho com computador, ler o caderno didático fazer um trabalho e entregar, raramente tinha esses momentos de compartilhamento que eram os bons. Então esses raros foram bons, mas foram poucos e não deu-se conta de tudo, eu espero que esse ano seja diferente por que mudou a orientadora, mas era muito separado a metodologia utilizada não foi tão satisfatória quanto o material. (Professora B, rede estadual)

Na questão do curso, metodologia, do conteúdo do curso deixa a desejar, se eu levar a apostila para casa lê eu vou sair ganhando muito mais, do que ficando lá. (Professora A, rede municipal) 
Encontrou-se evidencias que indicam o Programa como sendo uma formação com devida relevância, mas sua concretização não foi ao encontro com a qualidade do material disponibilizado. As dinâmicas organizacionais também são destacadas pela professora A como aspectos que fragilizaram as ações de formação:

As apostilhas são boas, demoraram muito para vir, e não tem material, se tem como baixar, tu conseguias, eu acho ela é bem bom, bem interessante ajuda bastante tem ideias boas, mas é complicado no sentido daquela pessoa que passa o dia inteiro na escola continuar a noite se torna muito cansativo, no meu ponto de vista tinha que ser no sábado, mas não é todo mundo que concorda com isso, eu achei bom com alguns problemas o que me frustrou foi essa questão do material, não é meu se eu sair daqui o material tem que ficar aqui, o material é da escola. (colaboradora A, rede estadual).

Estas questões permitem inferir que os posicionamentos acerca do impacto do programa ainda são difíceis de serem identificadas com precisão. O programa deixou incertezas que possivelmente interferem em modificações significativas no contexto escolar. As narrativas docentes manifestam estes questionamentos:

O Pacto na verdade não teve, não foi um movimento que levou para frente à realidade da sala de aula ao ponto de mudar a sociedade, está mais em função de verba, de cumprir carga horária e de prestar conta disso para que a verba venha, ele como movimento nacional poderia fazer uma avalição as reais necessidades da escola do que os profissionais enfrentam. (professora $A$, rede municipal).

Eu acho que a formação continuada, ela deve existir, mas às vezes, percebo como o Pnaic que é um programa que vem uma verba federal, tem muitos momentos, que percebo que estamos lá cumprindo horário, por que eles têm prestar conta daquela verba, então à gente está lá para cumprir horário. Sendo eficaz, bem aproveitado, com temas pertinentes a escola. A sala de aula, não tem acontecido, por exemplo: uma abordagem que é a Lei afro-indígena que é uma coisa atual é Lei nunca foi abordado lá, foi abordada a inclusão, que já passou que já Lei há tanto tempo, está acontecendo em sala de aula, mas coisas novas que vem que nem é nova lei afro-indígena, mas agora que a gente está abordando então coisas que realmente importantes para a sala de aula para o nosso dia a dia, eu acho que falta, as palestras são coisas muito para cumprir carga horaria. O que tem o aproveitamento em si se dá nessas trocas que te falei. Na questão do curso, metodologia, do conteúdo do curso deixa a desejar. (professora A, rede municipal)

As narrativas apresentam a importância da formação continuada, mas que nem sempre se encontra com as demandas atuais do contexto escolar, assim deixando de abordar o que os professores consideram como exigências atuais no contexto escola. Para tal nos conduz a refletir sobre os desafios implicados na organização e planejamento dessas ações formativas. Há uma distância entre o que é propugnado nos programas de reforma educacional e o que é de fato praticado nas escolas apresenta uma grande defasagem. Desta forma, a importância de chegar-se ao contexto da escola para compreender as mudanças que de fato ocorrem no cotidiano docente (Oliveira, 2004). 


\section{Considerações finais}

Com base no estudo desenvolvido que objetivou compreender a repercussão das ações de formação promovidas pelo Pnaic nas práticas pedagógicas de professores na rede municipal e estadual de Santa Maria pode-se chegar a algumas considerações.

As professoras apontam que as ações formativas viabilizadas pelo Pnaic apresentaram aspectos favoráveis para a prática docente, sendo que esses parecem na forma de compartilhamento de vivências e saberes, assim como em situações motivadoras para o trabalho pedagógico.

Os posicionamentos favoráveis das docentes às dinâmicas formativas do Pnaic que proporcionaram o compartilhamento entre pares permitem indicar a modalidade de formação entre pares como dispositivo importante para o avanço do trabalho pedagógico no bloco de alfabetização, remetendo-nos a validação desta dinâmica nos programas de formação continuada.

As docentes indicam os grupos de estudo como impulsionadores para a reflexão de suas próprias práticas, especialmente, quando assumiram a função de compartilhar dúvidas, anseios, angústias, bem como propostas a serem desenvolvidas nas suas práticas docentes.

Outro ponto de destaque foram os cadernos de formação, que foram ressaltados como importante material de consulta e estudo dos professores. Entretanto, houve indicações negativas relativas aos modos organizacionais promovidos nas ações de formação, as quais revelam que o potencial do programa foi fragilizado por questões que dizem respeito à formação, preparação e a metodologia desenvolvida pelas orientadoras de estudos; distanciamento dos estudos organizados e realizados na formação, com as exigências do contexto escolar e provimento de condições para a qualificação efetiva dos processos educativos no bloco de alfabetização.

As professoras manifestam que as condições da formação no que se refere ao tempo e a sobrecarga de atividades propostas revelaram-se como impeditivos de potencial que a formação poderia ocorrer. As considerações elencadas pelas professoras nos conduzem a refletir sobre a gestão e suas implicações para o processo de formação promovido pelo Pnaic, tendo em vista que se evidenciou divergências de encaminhamentos originados dos diferentes atores envolvidos na gestão do programa, que em muitos casos contrariavam as próprias premissas do programa.

Ressaltando que o estudo tem em sua base de dados em dois grupos de docentes pertencentes à Rede Municipal e Estadual do município de Santa Maria, as quais são gestões diferenciadas, que se organizaram para o desenvolvimento do Pnaic de maneiras distintas, pelo evidenciado nas narrativas docentes. A imposição relatada pelas docentes da rede Municipal, não foi evidenciada nas narrativas das professoras da rede Estadual.

Com relação às orientadoras dos grupos estudo essas relatam pontos muito próximos. Ao passo que essas teriam por finalidade organizar de melhor forma possível os encaminhamentos para o desenvolvimento e efetivação do programa.

Nesta direção, percebe-se que mesmo que as gestões tenham sido diferenciadas, há a necessidade de refletir sobre seu papel e sua relação com a escola, ao passo que em sua constituição teórica compreende-se como processo social construído no coletivo, para tal requer a participação e colaboração de todos os sujeitos. 
As narrativas revelam indícios que nos conduzem a concluir que o diálogo e ações coletivas estão distanciadas tanto na escola, quanto entre a escola e a gestão local, demonstrando a fragmentação dos processos de gestão democrática. O estudo nos mostrou a importância das instâncias coletivas e colegiadas de gestão, pois foi evidenciado que esse distanciamento produz interferências negativas sobre o processo da formação continuada.

Pode-se perceber um descontentamento por parte das docentes com a condução do desenvolvimento das ações no que se refere às orientadoras de estudo, o que foi descrito como ponto negativo do programa, pois de acordo com as professoras as orientadoras tiveram dificuldades em desenvolver as atividades propostas.

Considera-se a necessidade de problematizar se isso não decorre de uma cultura de formação docente pautada no receituário e na recepção passiva. Mesmo que seja unânime nas narrativas docentes o reconhecimento que a formação continuada precisa ser um investimento pessoal, pode-se inferir que a construção do protagonismo docente, ainda, carece que ações mais efetivas.

Sendo que esse estudo propor-se a conhecer as possíveis interferências nas práticas pedagógicas das políticas públicas, em especial a do Pnaic, considera-se que esse promoveu algumas alterações sobre o contexto escola, mesmo que essas ainda não possam ser percebidas com clareza, mas um movimento que se considera importante foi o compartilhamento entre pares viabilizando as professoras situarem seus trabalhos dentro do contexto da rede da qual faz parte.

A emergência e a construção do protagonismo compartilhado revelam-se como desafio para a melhoria da educação, tornando possível visualizar a política educacional como agenciador desse processo em busca de um sistema educacional que possa promover a construção de conhecimento.

\section{Referências}

BRASIL. Pacto nacional pela alfabetização na idade certa: formação do professor alfabetizador: caderno de apresentação. Brasília: MEC, 2012.

BRASIL. Educação para todos: compromisso de Dakar. Brasília: Unesco, Consed, Ação Educativa, 2001.

BRASIL. Decreto n. 7.084 de 2010, Instituído o Pacto Nacional pela Alfabetização na Idade Certa, Diário oficial. Brasília, DF, 18 de dez. de 2012. Disponível em <http://pacto.mec.gov.br/images/pdf/port 1458 141212.pdf>. Acesso em 19 ago. 2015.

CHARLOT, Bernard. Da relação com o saber, elementos para uma teoria. Porto Alegre: Artmed, 2000.

DOURADO, LUIZ Fernandes, Políticas e gestão da educação básica no Brasil: limites e perspectivas. Educ. Soc., Campinas, v. 28, n. 100, 2007, p. 921-946.

GATTI, Bernadete Angelina; BARRETO, Elba S. S (coord.). Professores do Brasil: impasses e desafios. Brasília: Unesco, 2009.

GATTI, Bernadete Angelina. Análise das políticas públicas para formação continuada no Brasil, na última década. Revista Brasileira de Educação v. 13, n. 37, 2008, p. 57-70.

FREIRE, Paulo, Pedagogia da autonomia: saberes necessários à prática educativa. São Paulo: Paz e terra, 2002. 
OLIVEIRA, Dalila Andrade. Das políticas de governo à política de estado: reflexões sobre a atual agenda educacional brasileira, Educ. Soc., Campinas, v. 32, n. 115, 2004, p. 323337.

OLIVEIRA, Dalila Andrade, A reestruturação do trabalho docente: precarização e flexibilização. Educ. Soc., Campinas, v. 25, n. 89, 2004, p. 1127-1144.

TEIXEIRA, Celso Elenaldo. O papel das políticas públicas no desenvolvimento local e na transformação da realidade. Salvador: AATR-BA, 2002.

MARCELO, Carlos. Desenvolvimento profissional docente: passado e futuro. Revista de Ciências da Educação, n. 8, 2009, p. 7-22.

NÓVOA, António, Professores: imagens do futuro presente. Lisboa: Educa, 2009.

VAILLANT, Denise; MARCELO, Carlos, Ensinando a ensinar: as quatro etapas de uma aprendizagem. Curitiba: UTFRP, 2012.

SAVIANI, Dermeval. Formação de professores no Brasil: dilemas e perspectivas. Poíesis Pedagógica, Goiânia, v. 9, n. 1, 2011, p. 7-19.

Evanir Agostinho de Oliveira é pedagoga, especialista em Gestão Educacional e estudante do curso de Educação Especial da Universidade Federal de Santa Maria. Endereço: Av. Roraima, 1000, prédio 16, sala 3336B - 97105-900 - Santa Maria Rio Grande do Sul - Brasil.

E-mail: agostinhoevanir@yahoo.com.br.

Ana Carla Hollweg Powaczuk é professora no Departamento de Metodologia do Ensino da Universidade Federal de Santa Maria.

Endereço: Av. Roraima, 1000, prédio 16, sala 3336B - 97105-900 - Santa Maria Rio Grande do Sul - Brasil.

E-mail: anapowaczuk@hotmail.com.

Recebido em 8 de outubro de 2016.

Aceito em 12 de dezembro de 2016. 